Kun Dai

Yunbo Li

Jiaye Gong

Zheng $\mathrm{Fu}$

Ang $\mathrm{Li}$

Dapeng Zhang

http://dx.doi.org/10.21278/brod73103

ISSN 0007-215X

eISSN $1845-5859$

\title{
NUMERICAL STUDY ON PROPULSIVE FACTORS IN REGULAR HEAD AND OBLIQUE WAVES
}

UDC 629.5.016.7:629.5.016:629.543

Original scientific paper

\begin{abstract}
Summary
This paper applies Reynolds-averaged Navier-Stokes (RANS) method to study propulsion performance in head and oblique waves. Finite volume method (FVM) is employed to discretize the governing equations and SST $k-\omega$ model is used for modeling the turbulent flow. The free surface is solved by volume of fluid (VOF) method. Sliding mesh technique is used to enable rotation of propeller. Propeller open water curves are determined by propeller open water simulations. Calm water resistance and wave added resistances are obtained from towing computations without propeller. Self-propulsion simulations in calm water and waves with varying loads are performed to obtain self-propulsion point and thrust identify method is use to predict propulsive factors. Regular head waves with wavelengths varying from 0.6 to 1.4 times the length of ship and oblique waves with incident directions varying from $0^{\circ}$ to $360^{\circ}$ are considered. The influence of waves on propulsive factors, including thrust deduction and wake fraction, open water, relative rotative, hull and propulsive efficiencies are discussed.
\end{abstract}

Key words: Propulsive factors; RANS; self-propulsion; head and oblique waves

\section{Introduction}

With the introduction of the Energy Efficiency Design Index (EEDI) by the International Maritime Organization (IMO) as a mandatory regulation to reduce fuel consumption and carbon emissions, it has been strongly demanded to improve the operational efficiency of ships when travelling in a seaway. In the EEDI formula for improving operational efficiency of ships, a weather factor is included [1], which is dependent of wave added resistance and propeller propulsive performance. Therefore, it has become more important to study the influence of waves on resistance and propulsive performance of a ship. 
Researchers have conducted numerous studies on the resistance and motions of a ship in waves based on experiments [2-5], potential theory [6-9] and computational fluid dynamics (CFD) approach [10-14]. Generally, the wave added resistance depends on hull shape, ship motions, travelling speed and the length, height and heading of wave [15], etc. The wave added resistance can be attributed to three components [16], which are the radiation effect, diffraction effect and viscous effect. The first one comes from interaction between the incident waves and the radiated waves caused by ship motions, especially caused by heave and pitch. The latter one is obtained from the wave diffractions and it is dominant in short waves. The last one is caused by the damping of the vertical motions. Although a lot of research has been done on the added resistance in waves, most of the focus is on the heading wave condition, while the research on the added resistance in waves under oblique waves is rarely reported.

Traditionally, investigations on propulsive performance in waves are performed by experiments. Moor and Murdey [17] conducted self-propulsion model tests for three kinds of ships in loaded and ballast conditions in head regular waves. The results showed that the largest variation of the propulsive factors for the wavelength equal to the ship length. Ueno et al. [18] performed free running tests to estimate the effective inflow velocity to propeller in waves. It was indicated that the effective wake fraction decreases as the propeller loading increases. Seo et al. [19] employed self-propulsion tests to investigate power increase and propulsive characteristics in regular head waves. The results suggested that propulsive factors in waves decrease with wave steepness. Saettone et al. [20] conducted load-varying selfpropulsion model tests regular head and following waves for a single screw container ship. The results of the experiments showed both the propeller loading and motions of ship affect the wake fraction. The wake fraction was found to decrease in head waves while increase in following waves, compared to calm water. In recent years, CFD method based on solving Navier-Stokes equations has been gradually applied to predict the propulsive performance in waves, showing good application prospects. Sigmund et al. [21] investigated effects of head waves on propulsion characteristics of a single and a twin-screw ship based on a RANS solver. The numerical results showed good agreement with the experimental data. Lee et al. [22] discussed the power increase and propulsive behaviour of KVLCC2 ship in regular head short waves using CFD tools. Polyzos et al. [23] presented a hybrid method combining experimental results and CFD calculations for predicting the propulsion characteristics of a ship in irregular head seas. The findings suggest that most of the previous work has focused on propulsive performance in head waves, while the oblique wave condition has been rarely mentioned. Due to the fact that ships operating in seaway experience various head directions, it is essential to understand how the propulsive factors change in oblique wave conditions.

This paper numerically investigates propulsive performance of the KVLCC2 model ship under $F r=0.142$ in head waves as well as in oblique waves using the RANS solver of CFD software STAR-CCM+. The length of head wave varies from 0.6 to 1.4 times the length of ship with 0.2 interval and the incident direction of oblique waves varies from $0^{\circ}$ to $360^{\circ}$ with $45^{\circ}$ interval are taken into account. Firstly, propeller open water curves and resistance in calm water and waves are computed. Next, self-propulsion in calm water and waves with varying loadings are simulated. Subsequently, the resistance, propeller rotation rate as well as thrust and torque at the self-propulsion point are determined by interpolation or extrapolation. Finally, the propulsive factor including thrust deduction and wake fraction, open water, relative rotative, hull and propulsive efficiencies are estimated with thrust identify method. The influence of waves on these propulsive factors is investigated. 


\section{Subject ship and calculation conditions}

The subject ship used in this study is KVLCC2, which is the second variant of a VLCC developed by the Korea Research Institute of Ships and Ocean Engineering (KRISO). The ship is fitted with a four-blade propeller named KP458 and a horn-type rudder. The main particulars of hull and details of propeller and rudder are listed in Table 1. For CFD simulations, a scale ratio of $1 / 110$ is adopted and the freeboard of hull is increased to avoid green water. The design speed is 15.5 knots in full scale, corresponding to $F r=0.142$ and $V=$ $0.76 \mathrm{~m} / \mathrm{s}$ in model scale. The geometry of the ship model is shown in Fig. 1. A right-handed coordinate system is adopted. The origin is fixed at the center of the ship, with $x$-axis pointing towards bow, $y$-axis pointing towards port and $z$-axis pointing towards upward.

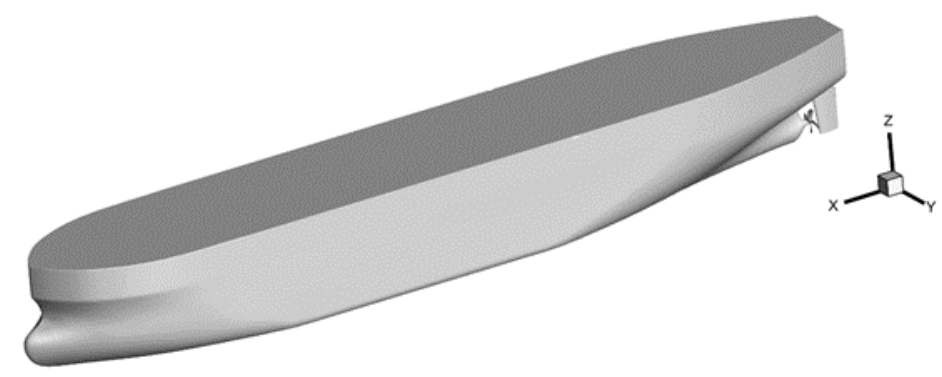

Fig. 1 Geometry of KVLCC2 tanker

Table 1 Data of KVLCC2

\begin{tabular}{|c|c|c|c|}
\hline Particulars & Symbols & Full scale & Model scale \\
\hline Scale & - & 1 & 110 \\
\hline Length between perpendiculars (m) & $L$ & 320 & 2.909 \\
\hline Length at the water line & $L_{W L}$ & 325.5 & 2.9591 \\
\hline Breadth $(\mathrm{m})$ & $B$ & 58 & 0.527 \\
\hline Draft $(m)$ & $T$ & 20.8 & 0.189 \\
\hline Displacement $\left(\mathrm{m}^{3}\right)$ & $\nabla$ & 312,622 & 0.235 \\
\hline Wetter area including rudder $\left(\mathrm{m}^{2}\right)$ & $S_{W}$ & 27,476 & 2.27 \\
\hline Longitudinal center of gravity, fwd+ $(\% L)$ & $L C G$ & 3.48 & 3.48 \\
\hline Vertical center of gravity $(\mathrm{m})$ & $V C G$ & 18.56 & \\
\hline Block coefficient & $C_{b}$ & 0.81 & 0.81 \\
\hline Radius of roll gyration & $i_{x x} / B$ & 0.4 & 0.4 \\
\hline Radius of pitch and yaw gyration & $i_{y y} / L, i_{z z} / L$ & 0.25 & 0.25 \\
\hline Number of propeller blades & $Z$ & 4 & 4 \\
\hline Propeller diameter $(\mathrm{m})$ & $D$ & 9.86 & 0.09 \\
\hline Pitch ratio $(0.7 \mathrm{R})$ & $P / D$ & 0.721 & 0.721 \\
\hline Area ratio & $A_{e} / A_{0}$ & 0.431 & 0.431 \\
\hline Propeller rotation & - & Right hand & Right hand \\
\hline Rudder wetted area $\left(\mathrm{m}^{2}\right)$ & $S_{R}$ & 273.3 & 0.0226 \\
\hline
\end{tabular}


The propeller open water simulations are performed by operating the propeller under undisturbed inflow conditions. The propeller rotation rate is fixed while the advance speed is varied to achieve different advance coefficient. The advance coefficient $J$, thrust coefficient $K_{T}$, torque coefficient $K_{Q}$ and open water efficiency $\eta_{0}$ are defined as follows:

$$
\begin{aligned}
& K_{T}=\frac{T}{\rho n^{2} D^{4}} \\
& K_{Q}=\frac{Q}{\rho n^{2} D^{5}} \\
& \eta_{0}=\frac{K_{T}}{K_{Q}} \frac{J}{2 \pi} \\
& J=\frac{V_{A}}{n D}
\end{aligned}
$$

where $\rho$ is the water density, $n$ is the rotation rate, $D$ is the diameter of propeller, $V_{A}$ is the advance speed.

The towing computation in calm water and waves are conducted under the ship design speed of $V=0.76 \mathrm{~m} / \mathrm{s}$ with the rudder fitted to the ship model. For calm water condition, the calm water resistance $R_{T C}$, trim $\tau$ and sinkage $\sigma$ are measured, and the resistance coefficient is defined as:

$$
C_{T C}=\frac{R_{T C}}{0.5 \rho S_{W} V^{2}}
$$

where $S_{W}$ is the wetted surface. For head wave conditions, the degrees of freedom of pitch and heave motions are free. The heave and pitch response amplitude operators (RAOs) are defined as follows:

$$
C_{Z}=\frac{Z_{a}}{\zeta_{a}} \quad C_{\theta}=\frac{\theta_{a}}{k \zeta_{a}}
$$

where $\zeta_{a}$ is wave amplitude, $k$ is wave number. $Z_{a}$ and $\theta_{a}$ are heave and pitch amplitude, respectively. The added resistance coefficient is defined as follows:

$$
C_{A W}=\frac{R_{A W}}{\rho g \zeta_{a}^{2} B^{2} / L}
$$

where $g$ is acceleration of gravity and $B$ is ship breath. $R_{A W}$ is the wave added resistance and it is calculated by $R_{A W}=R_{T W}-R_{T C}$. Here, $R_{T W}$ is the resistance in waves.

For self-propulsion simulations in calm water and waves, the propeller and rudder are fitted to the ship model. The heave and pitch motions are free under calm water condition, while additional degree of freedom of roll motion is released in wave conditions. The ship speed is kept constant at $V=0.76 \mathrm{~m} / \mathrm{s}$ while four values of propeller rotation rates are applied. The lowest value makes the thrust close to zero. The highest value ensures that the model is towed at the full-scale propulsion point under most conditions. The remaining two values are intermediate points. A skin friction correction force $F_{D}$ is added to self-propulsion computation to consider the reduction of the resistance due to friction difference between full 
scale and model scale. For self-propulsion in calm water or waves, the relationship between total resistance $R_{T}^{s p}$, thrust $T$ and towed force $T F$ is expressed as:

$$
T F=R_{T}^{s p}-T
$$

The self-propulsion point can be obtained by interpolation or extrapolation, where $T_{F}=$ $F_{D}$. Getting the self-prolusion point, the operating advance coefficient $J_{0}$, open water efficiency $\eta_{0}$ and torque coefficient $K_{Q O}$ can be obtained from the open water curves by applying the thrust identify method [24] with $K_{T}$ as an input data. Then, thrust deduction factor $t$, wake fraction $w$, relative rotative efficiency $\eta_{R}$, hull efficiency $\eta_{H}$ and propulsive efficiency $\eta_{D}$ can be calculated as follows:

$$
\begin{aligned}
& t=1-\left(R_{T}-F_{D}\right) / T \\
& w=1-\frac{J_{0} n D}{V} \\
& \eta_{R}=K_{Q 0} / K_{Q} \\
& \eta_{H}=(1-t) /(1-w) \\
& \eta_{D}=\eta_{H} \eta_{R} \eta_{0}
\end{aligned}
$$

The wave conditions for self-propulsion simulations are listed in Table 2 , in which $0^{\circ}$ means following wave and $180^{\circ}$ means head wave. The wave conditions for towing computation are the same as those given in Table 2, except that $225^{\circ}, 270^{\circ}$ and $315^{\circ}$ incident waves are not included. Because the resistance in $225^{\circ}, 270^{\circ}$ and $315^{\circ}$ incident waves can be considered the same as those in $135^{\circ}, 90^{\circ}$ and $45^{\circ}$ incident waves, respectively, according to the principle of symmetry.

Table 2 Wave condition for self-propulsion simulations

\begin{tabular}{|c|c|c|}
\hline Wave Direction $\chi\left(^{\circ}\right)$ & Wave height $H / L$ & Wave length $\lambda / L$ \\
\hline 180 & 0.02 & $0.6,0.8,1.0,1.2,1.4$ \\
\hline $0,45,90,135,225,270,315$ & 0.02 & 1.0 \\
\hline
\end{tabular}

\section{Numerical method}

\subsection{Governing equation and modeling}

The RANS solver of the CFD software Star-CCM+ is used for the numerical simulations. For the three-dimensional incompressible flows, the continuity and momentum equations are written in tensor notation as follows:

$$
\begin{aligned}
& \frac{\partial\left(\rho \bar{u}_{i}\right)}{\partial x_{i}}=0 \\
& \frac{\partial\left(\rho \bar{u}_{i}\right)}{\partial t}+\frac{\partial}{\partial x_{j}}\left(\rho \bar{u}_{i} \bar{u}_{j}+\rho \overline{u_{i}^{\prime} u_{j}^{\prime}}\right)=-\frac{\partial \bar{p}}{\partial x_{i}}+\mu \frac{\partial}{\partial x_{j}}\left(\frac{\partial \bar{u}_{i}}{\partial x_{j}}+\frac{\partial \bar{u}_{j}}{\partial x_{i}}\right)
\end{aligned}
$$


where $\bar{p}$ is the mean pressure, $\rho$ and $\mu$ define the density and dynamic viscosity of fluid, respectively. $\bar{u}_{i}$ is the averaged velocity vector and $\overline{u_{i}^{\prime} u_{j}^{\prime}}$ denotes the Reynolds stresses.

The finite volume method (FVM) is used to discretize the RANS equations. The SST k$\omega$ model is applied as the turbulence model. The convective terms are discretized using a second-order upwind scheme, the diffusion terms are discretized by a central differences scheme, and the temporal terms are discretized by adopting a second-order backward Euler scheme. The Semi-Implicit Method for Pressure-Linked Equations (SIMPLE) algorithm is applied to deal with pressure-velocity coupling. The volume of fluid (VOF) method is used to capture the evolution of free surface for the two-phase flow. For wave generation, a fifth order wave is modeled with a fifth order approximation to the Stokes theory of waves [25] with the given wave length, wave height and water depth. The all-Y+ treatment is employed for nearwall modeling, which applies wall function for coarse meshes and resolves viscous sub-layer for fine meshes. Dynamic Fluid Body Interaction (DFBI) module is applied to consider ship motions in specified directions.

\subsection{Computational domain and mesh generation}

The computational domain, boundary conditions and mesh for propeller open water (POW) simulations are shown in Fig 2. The cylindrical global domain is divided into a rotating part surrounding the propeller with cylindrical shape and a stationary part. The global domain extends $5 D$ upstream and laterally with a diameter of $10 D$. The dimension of the rotating cylinder is $0.3 D$ in axial direction and $1.2 D$ in radial direction. Velocity inlet and pressure outlet boundary conditions are imposed on the upstream and downstream planes, respectively. No-slip wall condition is specified at outer cylindrical side and surfaces of propeller and shaft. The computational domain is discretized by grids consist of hexahedral cells with trimmed mesh scheme. Prism layers are generated near the on the propeller and shaft surfaces and the wall grid spacing satisfies $30<y+<100$ as recommended by the ITTC [26] for wall function.
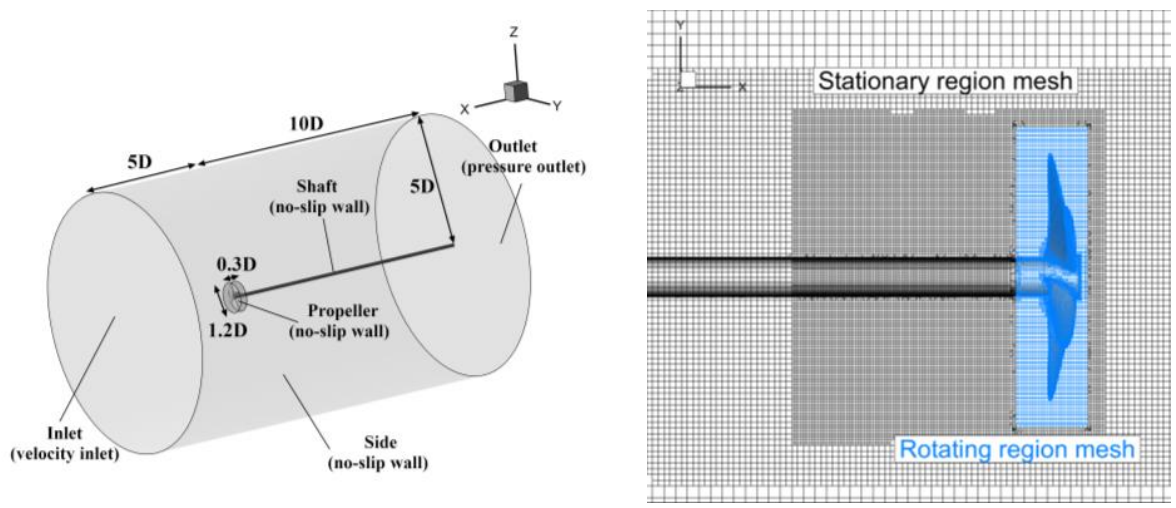

Fig. 2 Computational domain, boundary conditions and mesh for POW simulations

The computational domain and boundary conditions for towing computations and selfpropulsion simulations in calm water and waves are presented in Fig. 3. The inlet is $1.5 \mathrm{~L}$ forward of the bow, the outlet is $2.5 \mathrm{~L}$ behind the stern, and the sides are $2 \mathrm{~L}$ far from the centerline. The distances from the undisturbed free surface to the top and bottom are $0.9 \mathrm{~L}$ and $2 L$, respective. For boundary conditions, the inlet, outlet and side surfaces are set as velocity inlet, while the top surface is set as pressure outlet. No-slip wall condition is imposed on the bottom, hull and rudder surface. Wave forcing condition is imposed on the inlet, outlet and side boundaries to remove the wave oscillation. For computations in waves, the fifth order Stokes wave theory is applied for the velocity inlet and pressure outlet boundaries. 
An unstructured hexahedral mesh is generated for the computation with overset grid approach applied. Refinements of mesh are made near the free surface, hull and rudder. Prism layers are applied on hull and rudder surface, making the $y+$ range from 30 to 100. Fig. 4 shows the longitudinal section of the mesh. The grid used for self-propulsion calculation is the similar to that used for towing calculation, except that the propeller part is added. Fig. 5 shows the horizontal section of the mesh. For the computations in waves, further refinement of the grids near the free surface in order to better simulate the incoming regular waves. More than 50 cells (55-130 cells due to changes in wave length) per wave length and 16 cells per wave height are used. The grid number of self-propulsion computations in calm water and waves is listed in Table 3.

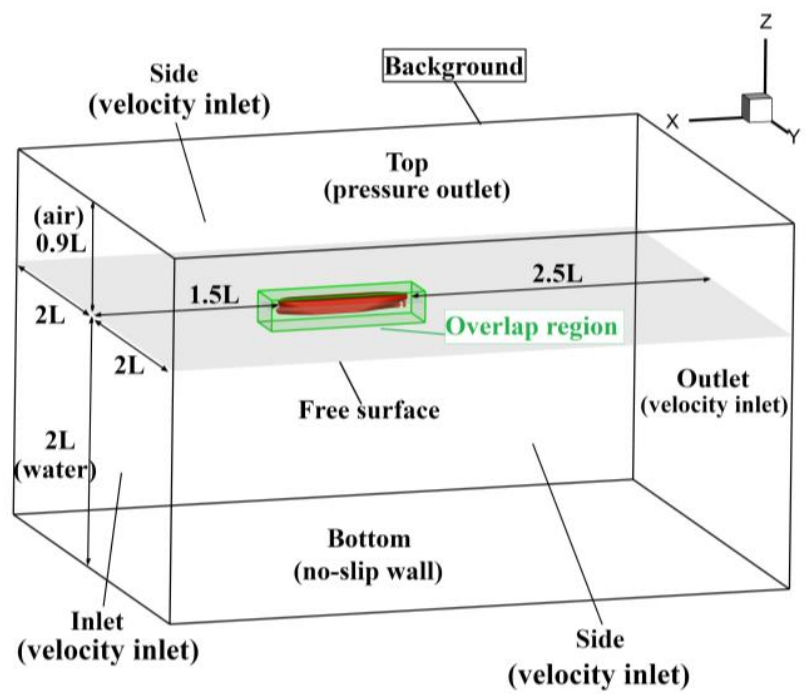

Fig. 3 Computational domain and boundary conditions for towing and self-propulsion computations
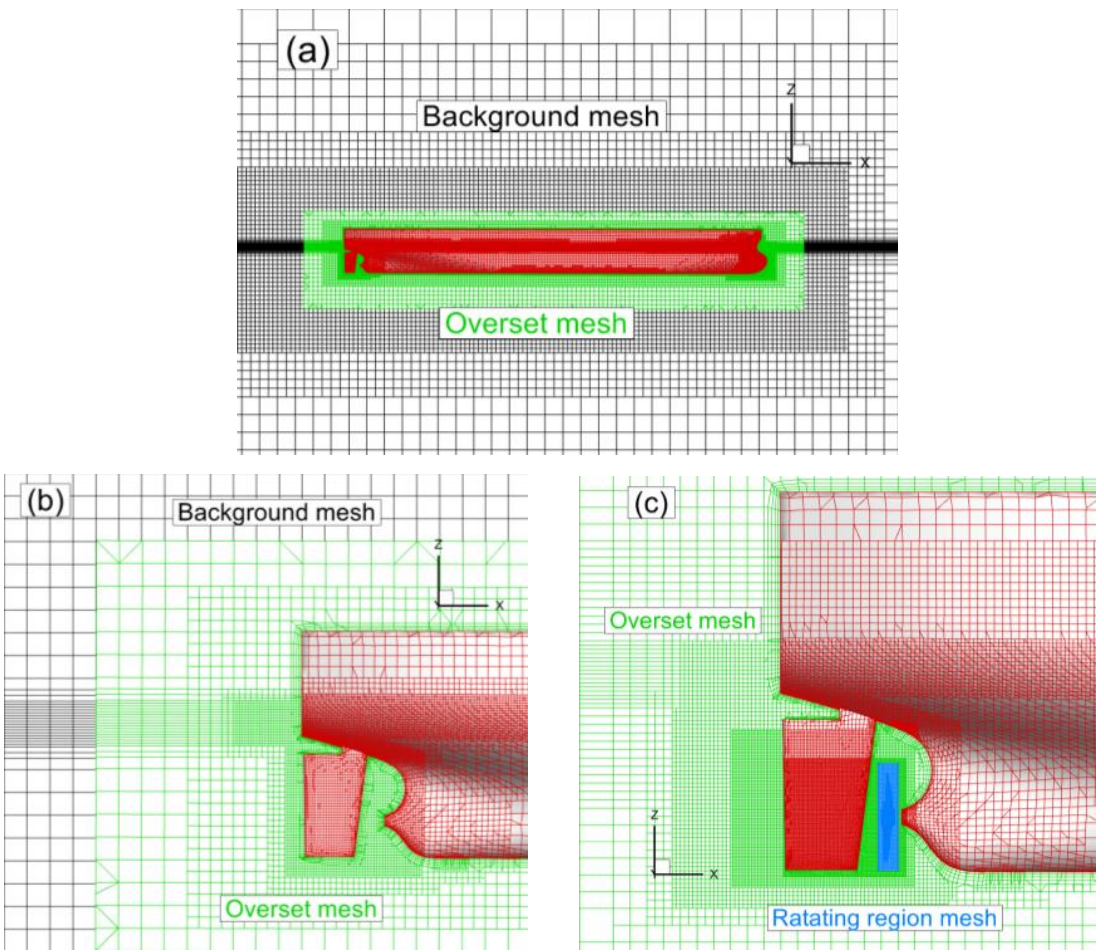

Fig. 4 Longitudinal section of the mesh: (a) overview (b) stern view of towing computation, (c) stern view of self-propulsion computation 
Table 3 Grid number of self-propulsion computations in calm water and waves

\begin{tabular}{|c|c|c|c|c|}
\hline Simulations & Background & Overset & Rotating region & Total \\
\hline Self-propulsion in calm water & $1.30 \mathrm{M}$ & $2.03 \mathrm{M}$ & $0.29 \mathrm{M}$ & $3.62 \mathrm{M}$ \\
\hline Self-propulsion in waves & $6.35 \mathrm{M}$ & $2.22 \mathrm{M}$ & $0.29 \mathrm{M}$ & $8.86 \mathrm{M}$ \\
\hline
\end{tabular}
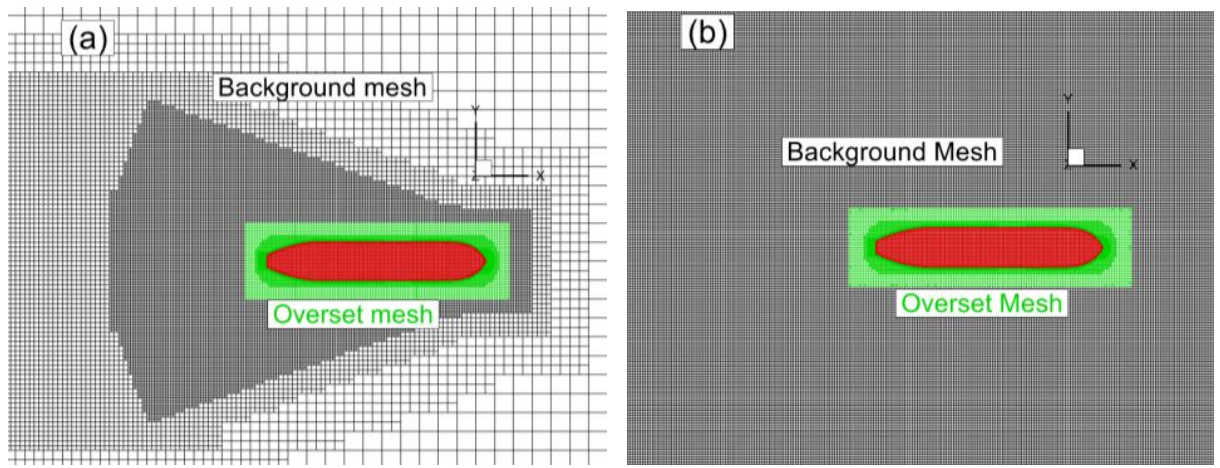

Fig. 5 Horizontal section of the mesh: (a) calm water condition, (b) wave condition

\subsection{Grid convergence study method}

The grid convergence is performed following the method presented by Stern et al. [27] and Wilson et al. [28]. The convergency ratio $R_{G}$ is defined as:

$$
R_{G}=\varepsilon_{21} / \varepsilon_{32}
$$

where $\varepsilon_{21}=S_{2}-S_{1}, \varepsilon_{32}=S_{3}-S_{2} . S_{1}, S_{2}$ and $S_{3}$ denote the solutions for fine, medium and coarse grids, respectively. Three convergency conditions are possible as follows according to $R_{G}$ :

$$
\left\{\begin{array}{l}
\text { (1) Monotonic convergency: } 0<R_{G}<1 \\
\text { (2) Oscillatory convergency: } R_{G}<0 \\
\text { (3) Divergency: } R_{G}>1
\end{array}\right.
$$

For condition (3), grid convergency is not achieved and uncertainties cannot be estimated. For condition (2), the grid uncertainty is calculated as follows:

$$
U_{G}=\frac{1}{2}\left|S_{U}-S_{L}\right|
$$

where $S_{U}$ and $S_{L}$ are the oscillation maximums and minimums, respectively. For condition (3), the Richardson Extrapolation method is applied to estimate the one-term error $\delta^{*}{ }_{R E G}$ order of accuracy $p_{G}$ as follows:

$$
\begin{gathered}
\delta_{R E_{G}}^{*}=\frac{\varepsilon_{21}}{r_{G}^{p_{G}}-1} \\
p_{G}=\frac{\ln \left(\varepsilon_{32} / \varepsilon_{21}\right)}{\ln \left(r_{G}\right)}
\end{gathered}
$$

where $r_{G}$ is the grid refinement ratio. A correction factor is defined as:

$$
C_{G}=\frac{r_{G}^{p_{G}}-1}{r_{G}^{p_{\text {Gest }}}-1}
$$


where $P_{\text {Gest }}$ is the theoretical order of accuracy and $P_{\text {Gest }}=2$ is adopted in present study. The uncorrected uncertainty $U_{G}$ and corrected uncertainty $U_{G c}$ are given by:

$$
\begin{gathered}
U_{G}= \begin{cases}{\left[9.6\left(1-C_{G}\right)^{2}+1.1\right]\left|\delta_{R E_{G}}^{*}\right|} & \left|1-C_{G}\right|<0.125 \\
{\left[2\left|1-C_{G}\right|+1\right]\left|\delta_{R E_{G}}^{*}\right|} & \left|1-C_{G}\right| \geq 0.125\end{cases} \\
U_{G_{C}}= \begin{cases}{\left[\begin{array}{ll}
2.4\left(1-C_{G}\right)^{2}+0.1 \\
\left|1-C_{G}\right|\left|\delta_{R E_{G}}^{*}\right|
\end{array}\right.} & \left|1-\delta_{R E_{G}}^{*}\right|<0.25\end{cases}
\end{gathered}
$$

\section{Results and discussion}

\subsection{Propeller open water simulations}

The propeller open water tests of KP458 are simulated to obtain the open water characteristics which are necessary for predicting the self-propulsion factors. The POW computations are performed on the same scale as the experiment conducted by the National Maritime Research Institute of Japan (NMRI), and the numerical results are compared with the experimental results which are available from the SIMMAN 2014 [29].

The sliding mesh technique is employed to simulate the propeller operations. The propeller rotation rate remains unchanged at $n=43.62 \mathrm{rps}$, which are consistent with the NMRI experiment. The time step is set as $\Delta t=2.5 \times 10^{-4} \mathrm{~s}$, corresponding to a rotation angle of 4 degrees. The grid convergence study is performed at $J=0.4$ with three sets of grids generated systematically based on a constant refinement ratio $r_{G}=\sqrt{2}$. The grid sizes are given in Table 4. The results of the convergency study are shown in Table 5. The thrust coefficient $K_{T}$, torque coefficient $K_{Q}$ and open water efficiency $\eta_{0}$ all show monotonic convergence with $R_{G}$ of $0.566,0.325$ and 0.425 , respectively. The grid uncertainty $U_{G}\left(\% S_{1}\right)$ ranges from $1.838 \%$ to $2.777 \%$ with an averaged value of $2.188 \%$. The convergency study suggests that the grid changes have limited effect on the results for the present range of grid size. Thus, the medium grid is used in the following propeller open water simulations.

Table 4 Grids for convergency study at $J=0.4$

\begin{tabular}{|c|c|c|c|}
\hline Grid name & Stationary region & Rotating region & Total \\
\hline Fine $(S 1)$ & $3.63 \mathrm{M}$ & $0.83 \mathrm{M}$ & $4.46 \mathrm{M}$ \\
\hline Medium $(S 2)$ & $1.35 \mathrm{M}$ & $0.36 \mathrm{M}$ & $1.71 \mathrm{M}$ \\
\hline Coarse $(S 3)$ & $0.53 \mathrm{M}$ & $0.18 \mathrm{M}$ & $0.71 \mathrm{M}$ \\
\hline
\end{tabular}

Table 5 Results of grid convergency study at $J=0.4$

\begin{tabular}{|c|c|c|c|c|c|c|c|c|c|}
\hline Items & $S 1$ & $S 2$ & $S 3$ & $R_{G}$ & $p_{G}$ & $C_{G}$ & $\begin{array}{c}U_{G} \\
\left(\% S_{1}\right)\end{array}$ & $\begin{array}{c}U_{G C} \\
\left(\% S_{1}\right)\end{array}$ & $\begin{array}{c}\text { Convergence } \\
\text { type }\end{array}$ \\
\hline$K_{T}$ & 0.1572 & 0.1556 & 0.1528 & 0.566 & 1.641 & 0.766 & 1.948 & 0.311 & Monotonic \\
\hline $10 K_{Q}$ & 0.2027 & 0.2052 & 0.2128 & 0.325 & 3.244 & 2.078 & 1.838 & 0.628 & Monotonic \\
\hline$\eta_{0}$ & 0.4936 & 0.4827 & 0.4572 & 0.425 & 2.472 & 1.356 & 2.777 & 0.577 & Monotonic \\
\hline
\end{tabular}


Fig. 6 presents the iso-surfaces of $Q=1000$ for different advance coefficients. It can be seen that the tip vortexes are well captured while its strength shows a weakening trend as advance coefficient increases. Fig. 7(a) compares open water curves of the numerical results with the experimental data and Fig. 7(b) shows the differences. The thrust coefficient $K_{T}$ is overestimated, while the torque coefficient $K_{Q}$ and open water efficiency $\eta_{0}$ are underestimated. The differences increase a lot around $J=0.75$ and $J=0.8$ because the values are close to zero. Generally speaking, the present method is acceptable to resolve the flow surrounding an operating propeller. Therefore, the grid system of the rotating region and time step strategy are suitable for the following self-propulsion simulations.
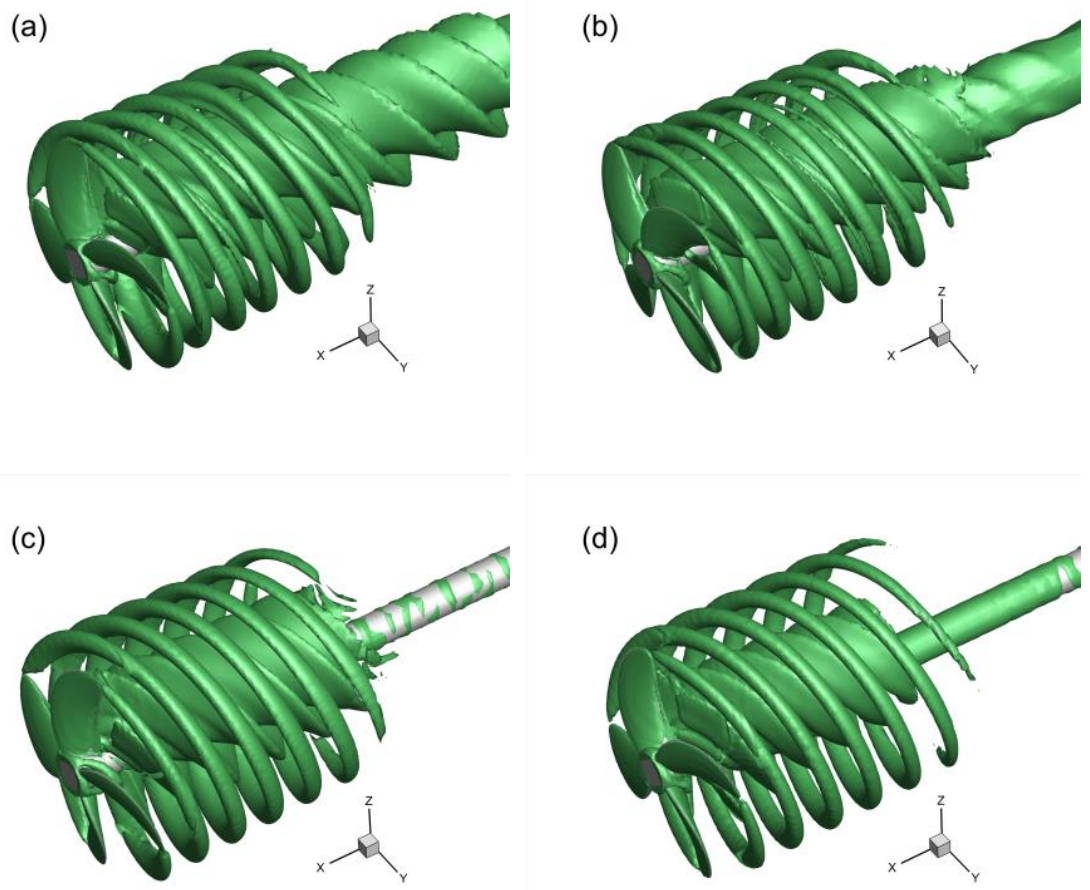

Fig. 6 Iso-surfaces of $Q=1000$ for different loading conditions: (a) $J=0.4$, (b) $J=0.5$, (c) $J=0.6$, (d) $J=0.7$

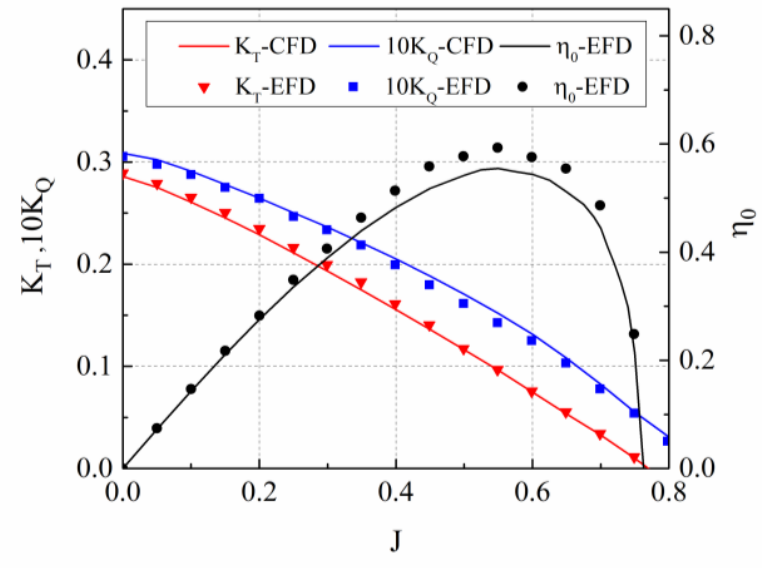

(a) Open water curves

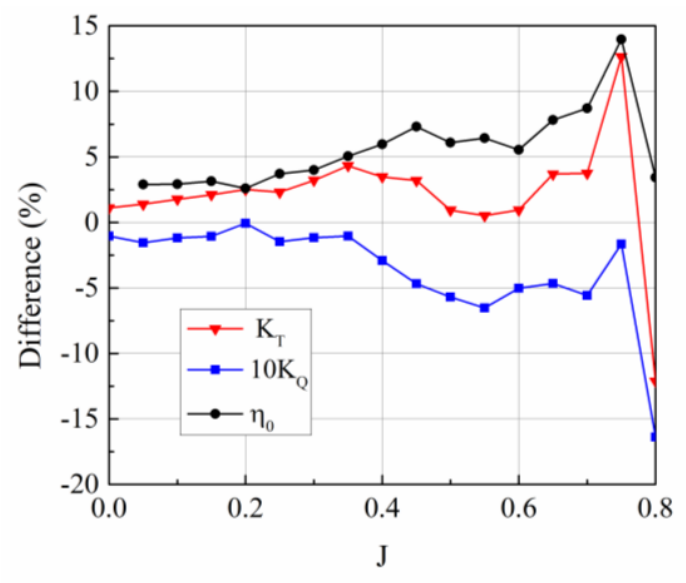

(b) Differences of experimental and computed results

Fig. 7 Propeller open water results 


\subsection{Towing computation in calm water}

A grid convergency study is also carried out for the towing computation in calm water. Details of the three grids with a refinement ratio of $r_{G}=\sqrt{2}$ are shown in Table 6 . The time step for the simulations is set to $\Delta t=2.0 \times 10^{-2} \mathrm{~s}$. Table 7 summarizes the results of grid convergency study. The resistance coefficient $C_{T C}$ achieves monotonic convergence with $R_{G}=$ 0.619 , while the sinkage $\sigma$ and trim $\tau$ show oscillatory convergence with $R_{G}$ of -0.667 and 0.0333 , respectively. For the three quantities, the grid uncertainties $U_{G}\left(\% S_{1}\right)$ are estimated within $2 \%$.

Table 6 Grids for convergency study for towing computation in calm water

\begin{tabular}{|c|c|c|c|}
\hline Grid name & Background & Overset & Total \\
\hline Fine $\left(S_{1}\right)$ & $2.88 \mathrm{M}$ & $2.08 \mathrm{M}$ & $4.96 \mathrm{M}$ \\
\hline Medium $\left(S_{2}\right)$ & $1.15 \mathrm{M}$ & $0.92 \mathrm{M}$ & $2.07 \mathrm{M}$ \\
\hline Coarse $\left(S_{3}\right)$ & $0.48 \mathrm{M}$ & $0.47 \mathrm{M}$ & $0.95 \mathrm{M}$ \\
\hline
\end{tabular}

Table 7 Results of grid convergency study for towing computation in calm water

\begin{tabular}{|c|c|c|c|c|c|c|c|c|c|}
\hline Items & $S 1$ & $S 2$ & $S 3$ & $R_{G}$ & $p_{G}$ & $C_{G}$ & $\begin{array}{c}U_{G} \\
\left(\% S_{1}\right)\end{array}$ & $\begin{array}{c}U_{G C} \\
\left(\% S_{1}\right)\end{array}$ & $\begin{array}{c}\text { Convergence } \\
\text { type }\end{array}$ \\
\hline$C_{T C}\left(\times 10^{3}\right)$ & 5.045 & 5.075 & 5.124 & 0.619 & 1.384 & 0.615 & 1.730 & 0.376 & Monotonic \\
\hline$\sigma / L\left(\times 10^{2}\right)$ & -0.097 & -0.095 & -0.098 & -0.667 & - & - & 1.546 & - & Oscillatory \\
\hline$\tau(\operatorname{deg})$ & -0.138 & -0.137 & -0.139 & -0.333 & - & - & 0.871 & - & Oscillatory \\
\hline
\end{tabular}

The results of towing computation in calm water from medium grid are shown in Table 8, compared with the experimental data provided by the Osaka University (OU) in the 2010 Gothenburg Workshop [30]. The calculated resistance matches excellently the EFD data, while the comparison error for sinkage $\sigma$ and trim $\tau$ is $-4.04 \%$ and $6.2 \%$, respectively. The computed wave pattern is presented in Fig. 8. The predicted wave cuts at different positions are compared with the experimental results from Kim et al. [31] as presented in Fig 9. As shown in Fig. 9(a) and (b), the calculated wave cuts at the hull surface and at $y / L=0.0964$ agree well with the experimental results. But the calculated wave cuts at $y / L=0.1581$ and $y / L$ $=0.2993$ show oscillations in the interval of $-0.1<x / L<-0.6$, which are not in good agreement with the experimental results, shown as Fig. 9(c) and (d). This is likely due to insufficient grid refinement.

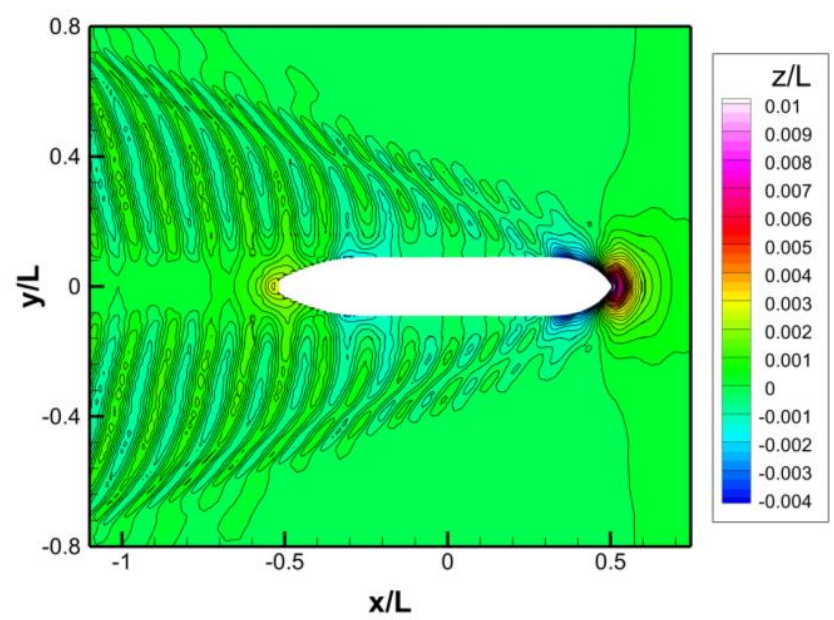

Fig. 8 Wave pattern for towing KVLCC2 in calm water 
Table 8 Computational and experimental results for resistance, trim and sinkage

\begin{tabular}{|c|c|c|c|}
\hline Items & CFD & EFD & $\mathrm{E}(\%)$ \\
\hline$C_{T C}\left(\times 10^{3}\right)$ & 5.075 & 5.093 & -0.35 \\
\hline$\sigma / L\left(\times 10^{2}\right)$ & -0.095 & -0.099 & -4.04 \\
\hline$\tau(\mathrm{deg})$ & -0.137 & -0.129 & 6.2 \\
\hline
\end{tabular}
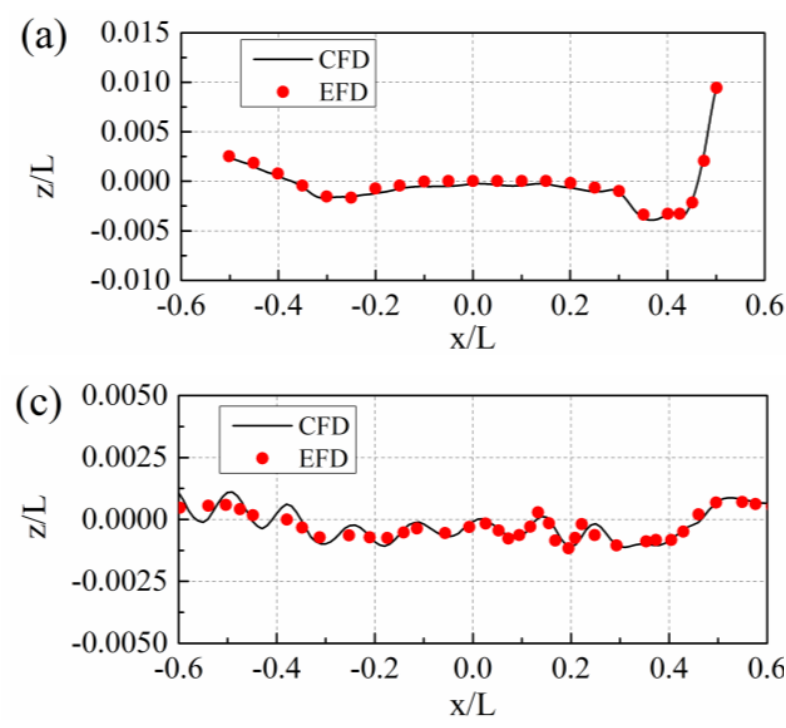
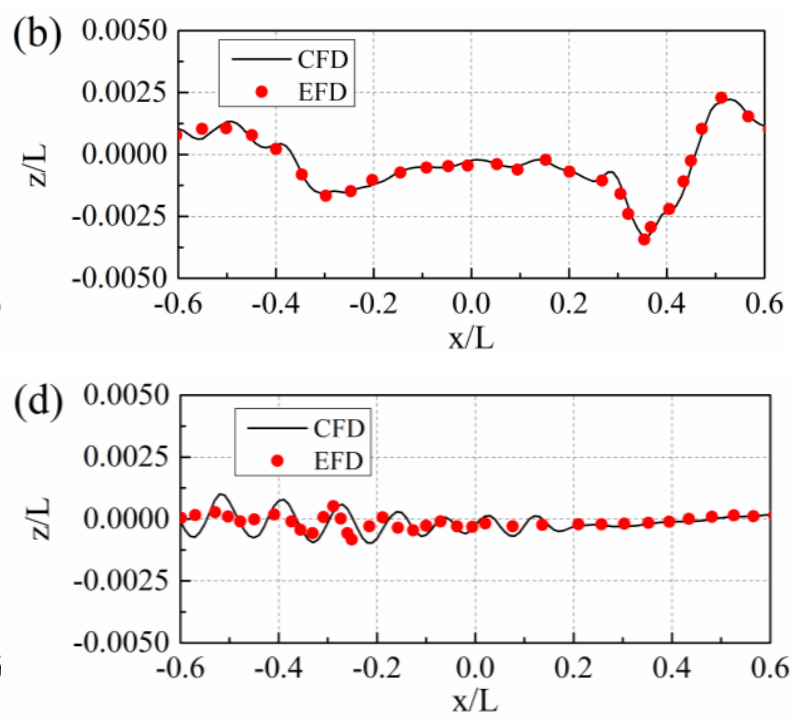

Figure 9 Wave cuts: (a) hull, (b) $y / L=0.0964$, (c) $y / L=0.1581$, (d) $y / L=0.2993$

\subsection{Towing computations in waves}

For towing computation in waves, the time step is set as $\Delta t=0.0025 \mathrm{~s}$ so that $\Delta t<T_{e} / 2^{8}$ for all incoming waves, where $T_{e}$ is the encounter period. Grid convergence study is performed at $\lambda / L=1.0$ using three grids with refinement ratio of $r_{G}=\sqrt{2}$, as shown in Table 9. The results of grid convergency study are summarized in Table 10. It can be seen that the added resistance coefficient $C_{A W}$ meets the monotonic convergency with $R_{G}=0.179$, while the heave and pitch RAOs show oscillatory convergency with $R_{G}$ of -0.325 and -0.698 , respectively. The grid uncertainty $U_{G}\left(\% S_{1}\right)$ ranges from $0.02 \%$ to $3.145 \%$ with an averaged value of $1.889 \%$. Next, the fine grid is applied for the simulations in different wave conditions.

Table 9 Grids for convergency study at $\lambda / L=1.0$

\begin{tabular}{|c|c|c|c|}
\hline Grid name & Background & Overset & Total \\
\hline Fine $\left(S_{1}\right)$ & $6.35 \mathrm{M}$ & $0.98 \mathrm{M}$ & $7.33 \mathrm{M}$ \\
\hline Medium $\left(S_{2}\right)$ & $2.66 \mathrm{M}$ & $0.49 \mathrm{M}$ & $3.15 \mathrm{M}$ \\
\hline Coarse $\left(S_{3}\right)$ & $0.89 \mathrm{M}$ & $0.23 \mathrm{M}$ & $1.12 \mathrm{M}$ \\
\hline
\end{tabular}

Table 10 Results of grid convergency study at $\lambda / L=1.0$

\begin{tabular}{|c|c|c|c|c|c|c|c|c|c|}
\hline Items & $S 1$ & $S 2$ & $S 3$ & $R_{G}$ & $p_{G}$ & $C_{G}$ & $\begin{array}{c}U_{G} \\
\left(\% S_{1}\right)\end{array}$ & $\begin{array}{c}U_{G C} \\
\left(\% S_{1}\right)\end{array}$ & $\begin{array}{c}\text { Convergence } \\
\text { type }\end{array}$ \\
\hline$z / \zeta_{a}$ & 0.4166 & 0.4251 & 0.3989 & -0.325 & - & - & 3.145 & - & Oscillatory \\
\hline$\theta /\left(\zeta_{a} k\right)$ & 0.4400 & 0.4401 & 0.4399 & -0.698 & - & - & 0.020 & - & Oscillatory \\
\hline$C_{A W}$ & 6.5261 & 6.6177 & 7.1296 & 0.179 & 4.963 & 4.585 & 2.503 & 1.098 & Monotonic \\
\hline
\end{tabular}


Fig. 10 shows the wave added resistance coefficient and RAOs of heave and pitch motions in head and oblique waves. The numerical results for head waves are compared with experimental data from $\mathrm{Yu}$ et al. [3], Kim et al. [13] and OU (Osaka University) [29], as presented in Fig. 10(a)-(c), which indicates that present CFD method shows a reasonable agreement with EFD data.

From Fig. 10(d)-(f), it can be seen that in $90^{\circ}$ incident wave, the heave response reaches the peak while the pitch response falls to valley. Since the frequency of encounters varies with wave direction, the frequency of the motion responses changes. The motion response changes rapidly as the frequency of the motion response approaches its natural frequency. For the added resistance coefficient, it is tiny in $0^{\circ}, 45^{\circ}$ and $90^{\circ}$ incident waves but significant in $135^{\circ}$ and $180^{\circ}$ and the peak value appears in head wave $\left(\chi=180^{\circ}\right)$.

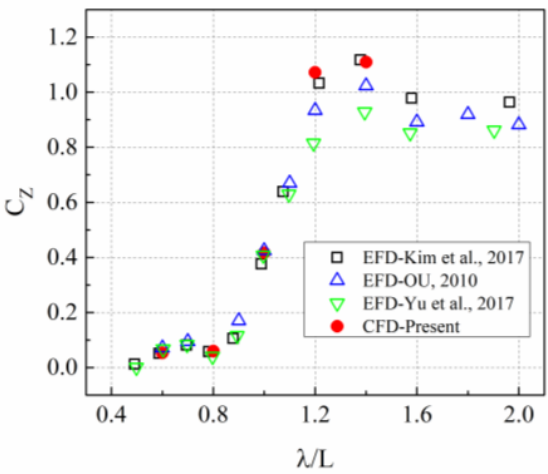

(a) Heave in head waves

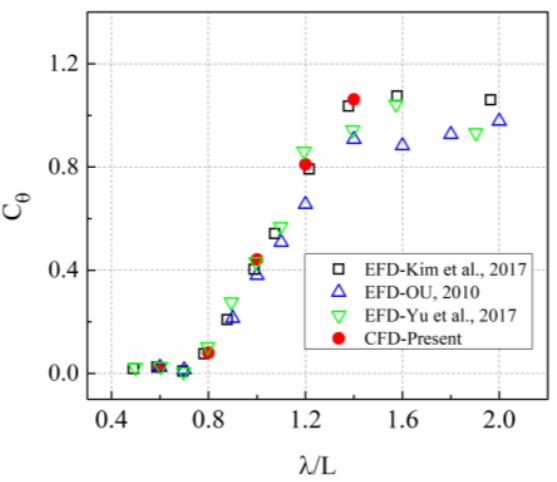

(b) Pitch in head waves

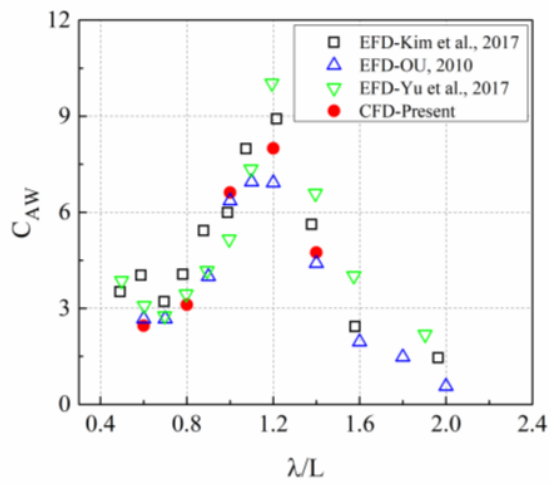

(c) Added resistance in head

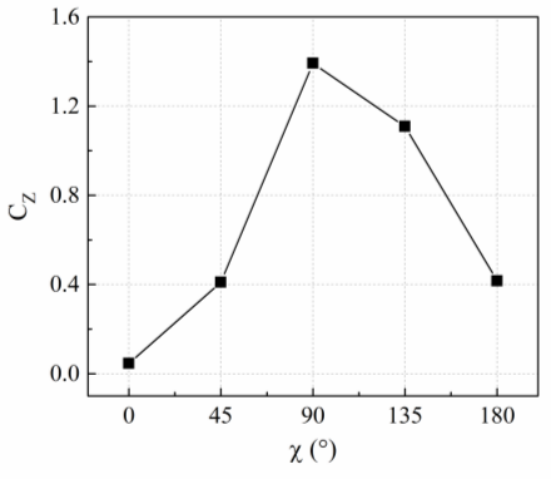

(d) Heave in oblique waves

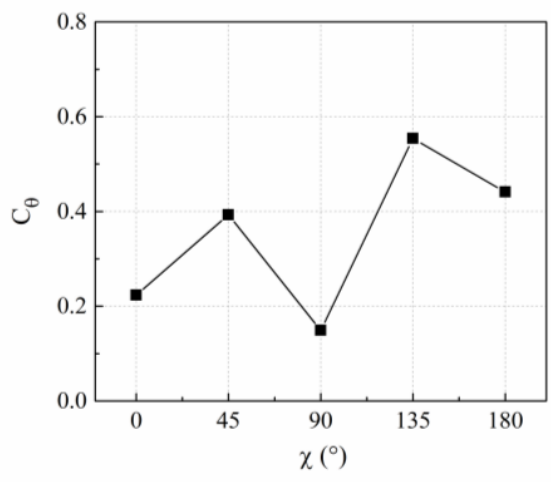

(e) Pitch in oblique waves

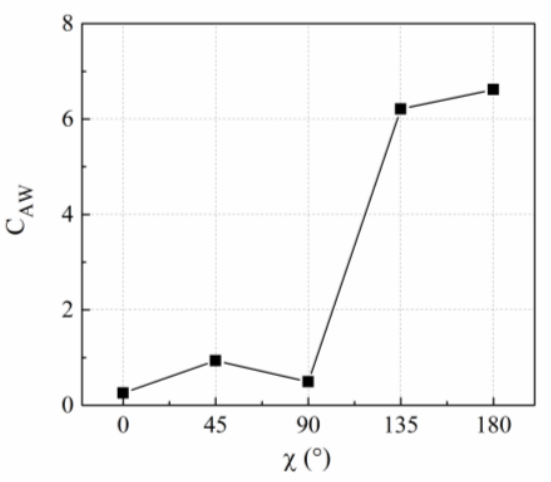

(f) Added resistance in oblique waves

Fig. 10 RAOs of motions and wave added resistance coefficient in head (left) and oblique waves (right) 


\subsection{Self-propulsion in calm water}

The skin friction correction force $F_{D}$ is calculated as follows:

$$
F_{D}=\frac{1}{2} \rho S_{W} V^{2}(1+k)\left[C_{F m}-\left(C_{F s}+\Delta C_{F}\right)\right]
$$

where the form factor $1+k=1.215$ is obtained by running a double-body computation. $C_{F m}=$ $4.085 \times 10^{-3}$ and $C_{F s}=1.396 \times 10^{-3}$ are friction factors at model and full scale, obtained from the ITTC 1957 model-ship correlation line, which is written as follows:

$$
C_{F}=\frac{0.075}{\left(\log _{10} R e-2\right)^{2}}
$$

The roughness allowance $\Delta C_{F}$ is estimated from:

$$
\Delta C_{F}=0.044\left[\left(k_{s} / L_{W L}\right)^{1 / 3}-10 R e^{-1 / 3}\right]+1.25 \times 10^{-4}
$$

where the ITTC recommended value $k_{s}=150 \times 10^{-6} \mathrm{~m}$ is used. The final result is $F_{D}=2.057 \mathrm{~N}$.

Fig. 11 shows the procedure to read off the propeller revolution $\mathrm{n}$, thrust $T$ and torque $Q$ at self-propulsion point by interpolating the self-propulsion calculation results at the value of $F_{D}$. The self-propulsion factors are listed in Table 11 . These coefficients are calculated using the numerical results of propeller open water diagram in Fig. 7. Full scale prediction is made according to the ITTC recommend method [32] and compared with data based on model test from Lee et al. [33]. As shown in Table 11, $\eta_{H}$ and $\eta_{R}$ show good agreement with experiment results, and the absolute values of errors are within 3.6\%. The $\eta_{0}$ and $\eta_{D}$ are underpredicted by $10.35 \%$ and $8.75 \%$, and these errors are related to the underpredicted open water efficiency, as shown in Fig.7.

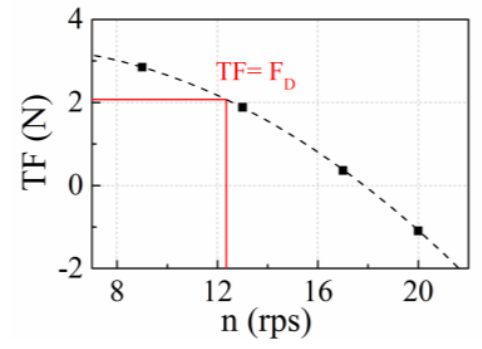

(a) $n$ vs $T F$

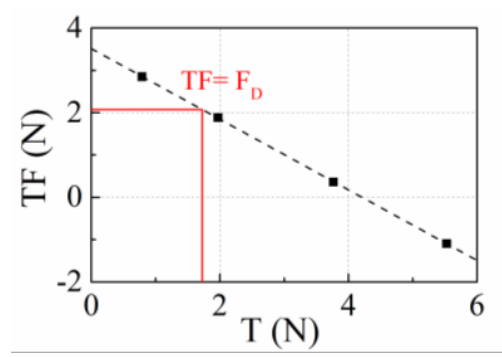

(b) $T$ vs $T F$

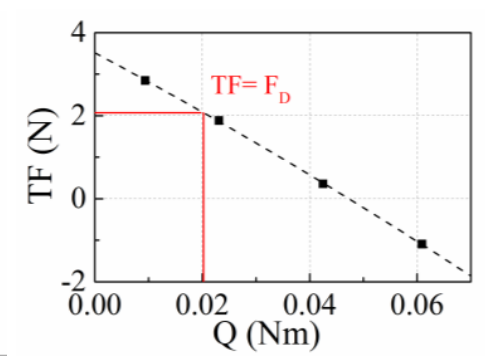

(c) $Q$ vs $T F$

Fig. 11 Procedure to obtain the self-propulsion point

Table 11 Self-propulsion factors in calm water

\begin{tabular}{|c|c|c|c|c|}
\hline \multirow{2}{*}{ Items } & \multirow{2}{*}{$\begin{array}{c}\text { Model scale- } \\
\text { present }\end{array}$} & \multicolumn{3}{|c|}{ Full scale } \\
\cline { 3 - 5 } & 0.259 & 0.259 & 0.239 & 8.37 \\
\hline$t$ & 0.485 & 0.367 & 0.330 & 11.21 \\
\hline$w$ & 1.439 & 1.171 & 1.135 & 3.17 \\
\hline$\eta_{H}$ & 1.005 & 1.005 & 1.042 & -3.55 \\
\hline$\eta_{R}$ & 0.436 & 0.485 & 0.541 & -10.35 \\
\hline$\eta_{0}$ & 0.630 & 0.584 & 0.640 & -8.75 \\
\hline$\eta_{D}$ & \multicolumn{3}{|c}{} \\
\hline
\end{tabular}




\subsection{Self-propulsion in waves}

The time-averaged towed force $F_{D}$ against propeller rotation rate $n$, time-averaged thrust $T$ and torque $Q$ with trendline in head wave of different wave lengths and in oblique waves with $\lambda / L=1$ are shown in Fig. 12 and Fig. 13, respectively. It can be seen that $T F$ shows good linear relationship with $T$ and $Q$ for all wave conditions, indicating that $t$ can be regarded as a constant for varying propeller loadings under the same wave condition, as mentioned by Bhattacharyya et al. [34]. In the case of the same propeller revolutions, the thrust under different wave conditions is not a constant, and the difference in thrust is more obvious under the oblique wave conditions. This suggests that the presence of waves causes changes in the wake fraction.
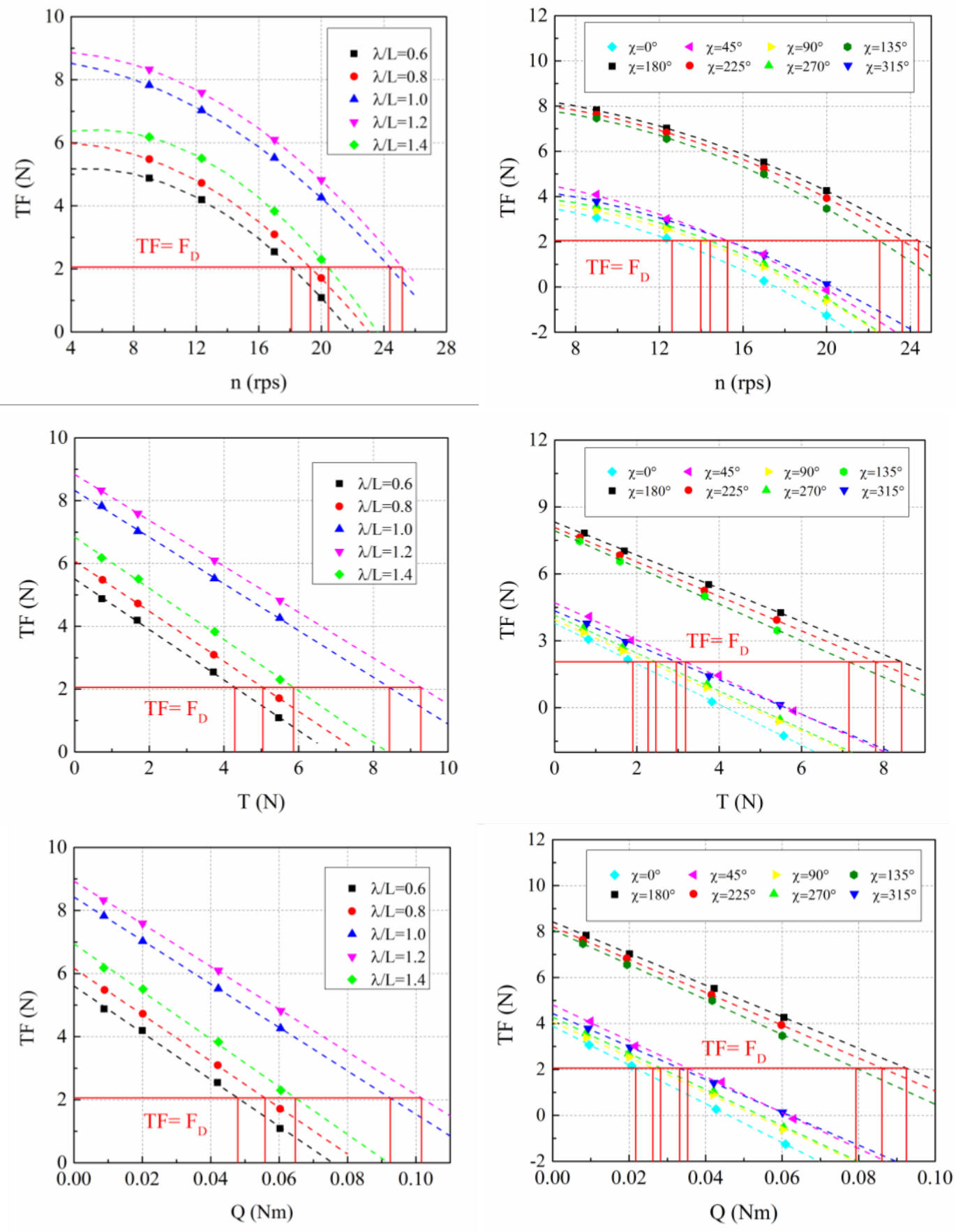

Fig. $12 T F$ versus $n, T$ and $Q$ in head waves

Fig. $13 T F$ versus $n, T$ and $Q$ in oblique waves 
The propulsive factors in head wave of different wave lengths are displayed in Fig. 14, compared with those of results in calm water. As shown in Fig. 14(a), the thrust deduction factor decreases in head waves, which shows that the proportion of resistance increase is larger than the proportion of thrust increase. From Fig. 14(b) and (f), it can be seen that the wake fraction and propulsive efficiency generally decrease compared to calm water, and the minimum values occur at $\lambda L=1$. Compared to calm water, the wake fraction and propulsive efficiency reduce by at most $25.2 \%$ and $42.6 \%$, respectively. As shown in Fig.14(c), the hull efficiency decreases in the range $\lambda / L=0.6-1.2$, while increase at $\lambda / L=1.4$. The increase in hull efficiency at $\lambda / L=1.4$ is due to the reduction in thrust deduction factor much larger than the reduction in wake fraction, according to Eq. (12). As shown in Fig. 14(d), there is a slight change in relative rotative efficiency in head waves and the difference is less than $2 \%$ compared to calm water. A general decrease for open water efficiency is shown in Fig. 14(e). The minimum value appears at $\lambda / L=1.2$ where the added resistance is highest, with $36.3 \%$ less than the open water efficiency in calm water.

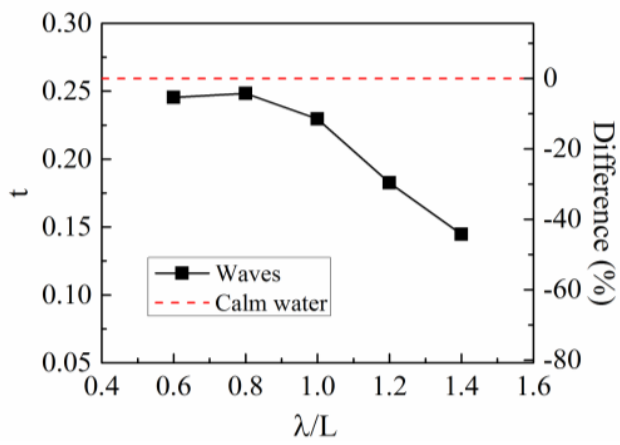

(a) Thrust deduction factor

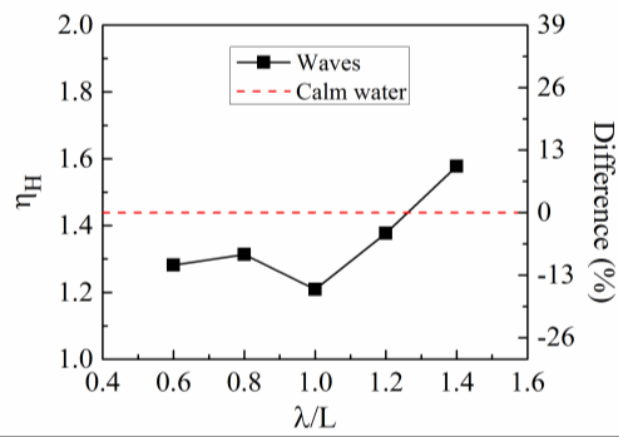

(c) Hull efficiency

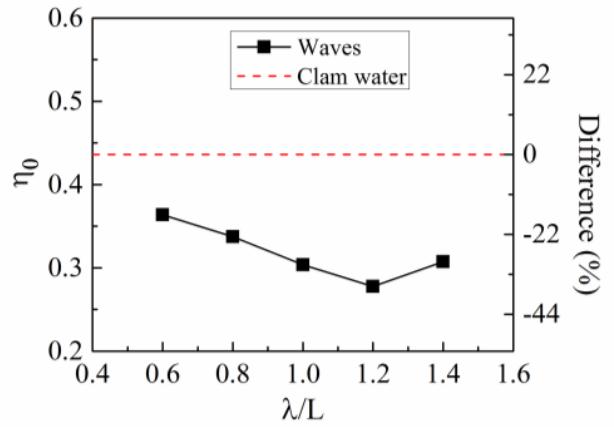

(e) Open water efficiency

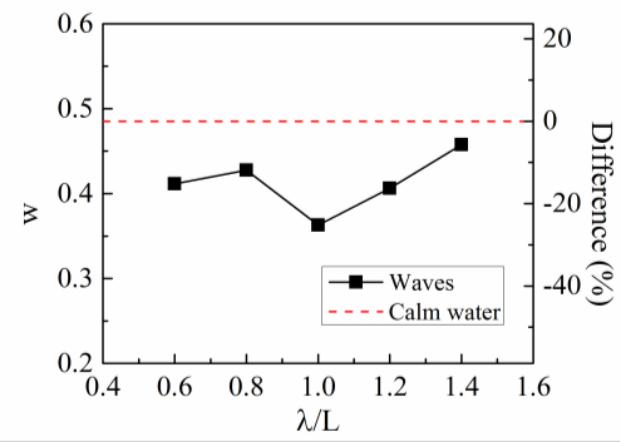

(b) Wake fraction

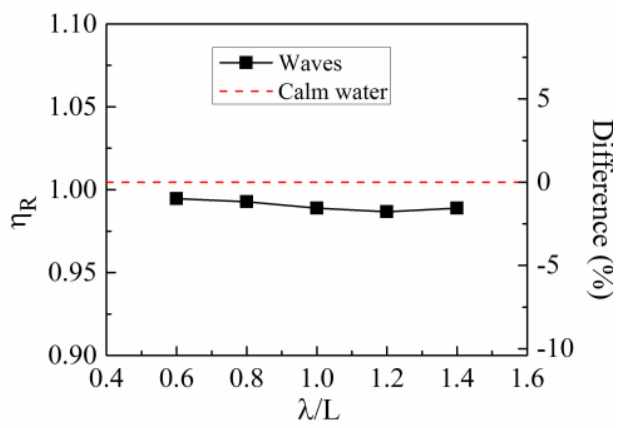

(d) Relative rotative efficiency

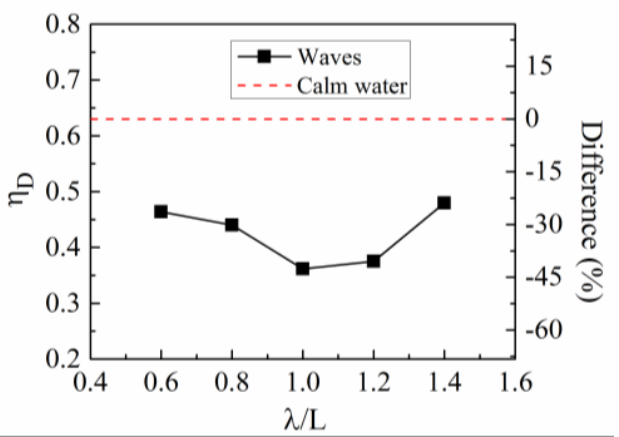

(f) Propulsive efficiency

Fig. 14 Propulsive factors in head wave of different wave lengths

The propulsive factors in oblique waves with $\lambda / L=1$ are presented in Fig. 15, compared with those of results in calm water. As shown in Fig. 15(a), compared to the calm water, the 
thrust deduction factor increases under $45^{\circ}, 90^{\circ}, 270^{\circ}$, and $315^{\circ}$ incident wave conditions with maximum increment of $42.5 \%$, while decreases under other wave direction conditions with maximum reduction of 47.2\%. As shown in Fig.15(b), (c) and (f), the wake fraction, hull efficiency and propulsive efficiency show a general decreasing trend in oblique waves compared to calm water, except for a slight increase in $0^{\circ}$, i.e., the following wave, which may be caused by the direct interaction between the propeller and encountered wave. The minimum values all occur in $180^{\circ}$, i.e., the head wave, with reduction of $25 \%, 16 \%$ and $42.4 \%$ for $w, \eta_{H}$ and $\eta_{D}$, respectively. As displayed in Fig. 15(d), the relative rotative efficiency $\eta_{R}$ shows little change in waves of different direction. From Fig.15(e), a general decrease in the open water efficiency $\eta_{0}$ is shown and the valley appears in head wave condition, where the propeller loading increases the most, with maximum reduction of $30.4 \%$ compared to calm water. It is worth noting that $t$ and $w$ are not symmetrical in the port and starboard incident waves. This is because for the ship with single operating propeller, the flow field near the stern is asymmetrical in the case of port and starboard incident waves. As a consequence, $\eta_{H}$ also shows asymmetry according to Eq. (12).

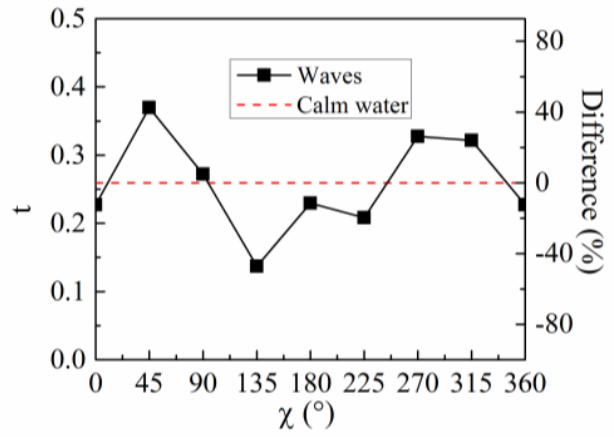

(a) Thrust deduction factor

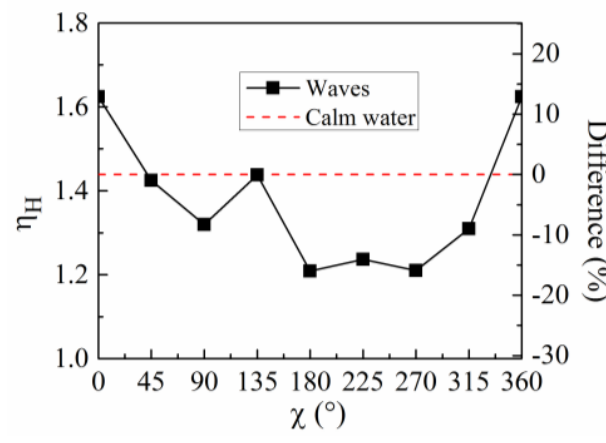

(c) Hull efficiency

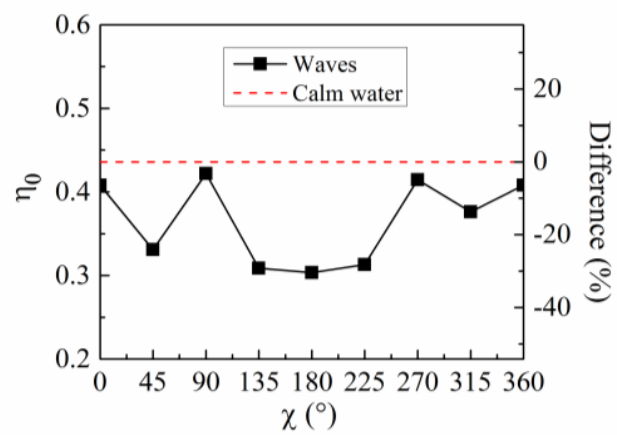

(e) Open water efficiency

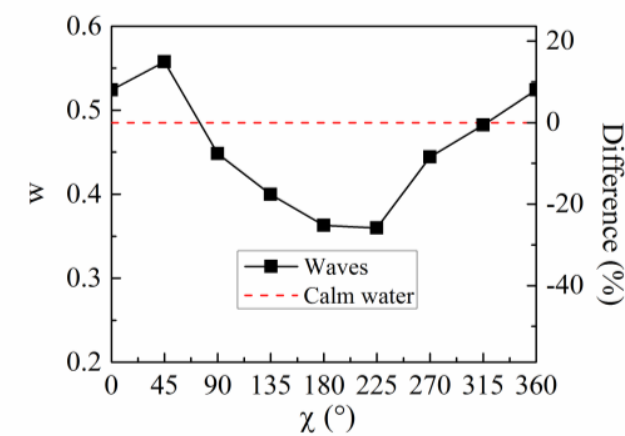

(b) Wake fraction

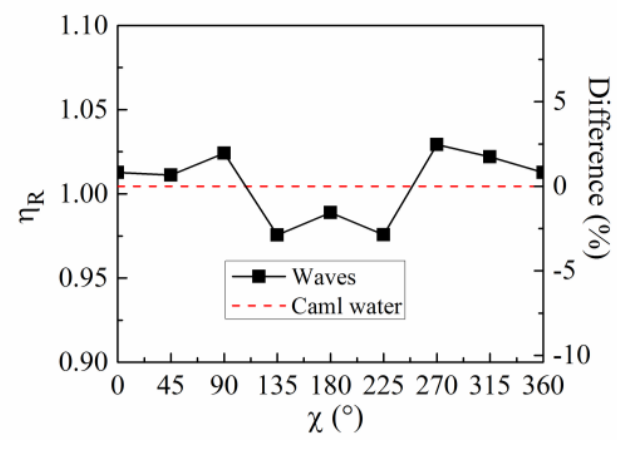

(d) Relative rotative efficiency

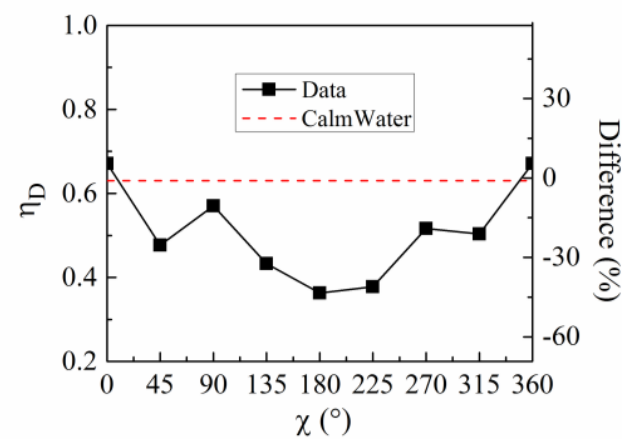

(f) Propulsive efficiency

Fig. 15 Propulsive factors in oblique waves with $\lambda / L=1$ 


\section{Conclusions}

In this paper presents numerical study on the influences of head and oblique waves on the propulsive factors by applying CFD tools. Simulations of propeller in open water and towing model in calm water and waves are performed after grid convergency study. Open water curves, resistance and motions in calm water and waves are obtained from the computations and compared to available experiment data to valid the numerical method. Then, self-propulsion in calm water and waves are simulated and propulsive factors are determined.

It is found that the self-propulsion point changes as the propeller loading increases in order to balance the increase in resistance caused by waves. In head waves, the thrust deduction factor, wake fraction, open water efficiency and propulsive efficiency generally decrease. Meanwhile, the wake fraction and propulsive efficiency reach the minimum when the wavelength is equal to the length of the ship. The hull efficiency shows a decreasing trend except at $\lambda / L=1.4$, which is due to the reduction in thrust deduction fraction much larger than the reduction in wake fraction at $\lambda / L=1.4$. The relative rotative efficiency is almost unchanged at different wave lengths.

In oblique waves, wake fraction, hull efficiency and propulsive efficiency show a general decreasing trend in oblique waves compared to calm water, except for a slight increase in the following wave, which may be due to the direct interaction between the propeller and encountered wave. Similar to the behavior in head wave conditions, the relative rotative efficiency shows little change. Furthermore, the asymmetrical flow field near the stern when the ship with single operating propeller encounters port and starboard incident waves causes asymmetry of thrust deduction fraction, wake fraction as well as hull efficiency.

In a future study, the effect of wave height on the propulsive factors will be discussed and various ship speeds will be considered.

\section{ACKNOWLEDGEMENT}

This work is supported by the National Natural Science Foundation of China (Grant No. 519791570) and the Natural Science Foundation of Shanghai, China (Grant No. 19ZR1422500).

\section{REFERENCES}

[1] Shin, H.W., Paik, K.J., Jang, Y.H., Eom, M.J., Lee, S., 2020. A numerical investigation on the nominal wake of KVLCC2 model ship in regular head waves. International Journal of Naval Architecture and Ocean Engineering, 12, 270-282. https://doi.org/10.1016/j.ijnaoe.2020.01.001

[2] Lee, J., Park, D.M., Kim, Y., 2017. Experimental investigation on the added resistance of modified KVLCC2 hull forms with different bow shapes. Proceedings of the Institution of Mechanical Engineers Part M, 231, 395-410. https://doi.org/10.1177/1475090216643981

[3] Yu, J.W., Lee, C.M., Choi, J.E., Lee, I., 2017. Effect of ship motions on added resistance in regular head waves of KVLCC2. Ocean Engineering, 146, 375-387. https://doi.org/10.1016/j.oceaneng.2017.09.019

[4] Park, D.M., Lee, J.H., Jung, Y.W., Lee, J., Kim, Y., 2019. Gerhardt, F. Experimental and numerical studies on added resistance of ship in oblique sea conditions. Ocean Engineering, 186, 106070. https://doi.org/10.1016/j.oceaneng.2019.05.052.

[5] Degiuli, N., Farkas, A., Martic, I., Zeman, I., Ruggiero, V., Vasiljevic, V., 2021. Numerical and experimental assessment of the total resistance of a yacht. Brodogradnja, 72(3), 61-80. https://doi.org/10.21278/brod72305

[6] Fang, M.C., Chen, G.R., 2006. On the nonlinear hydrodynamic forces for a ship advancing in waves. Ocean Engineering, 33, 2119-2134. https://doi.org/10.1016/j.oceaneng.2005.11.006

[7] Liu, S., Papanikolaou, A., Zaraphonitis, G., 2010. Prediction of added resistance of ships in waves. Ocean Engineering, 38, 641-650. http://dx.doi.org/10.1016/j.oceaneng.2010.12.007

[8] Seo, M.G., Park, D.M., Yang, K.K., Kim, Y., 2013. Comparative study on computation of ship added resistance in waves. Ocean Engineering, 73, 1-15. https://doi.org/10.1016/j.oceaneng.2013.07.008 
[9] Kim, K.H., Kim, Y., 2011. Numerical study on added resistance of ships by using a time domain Rankine panel method. Ocean Engineering, 38, 1357-1367. https://doi.org/10.1016/j.oceaneng.2011.04.008

[10] Orihara, H., Miyata, H., 2003. Evaluation of added resistance in regular incident waves by computational fluid dynamics motion simulation using an overlapping grid system. Journal of Marine Science and Technology, 8, 47-60. https://doi.org/10.1007/s00773-003-0163-5

[11] Guo, B.J., Steen, S., Deng, G.B., 2012. Seakeeping prediction of KVLCC2 in head waves with RANS. Applied Ocean Research, 35, 56-67. https://doi.org/10.1016/j.apor.2011.12.003

[12] Park, D.-M., Kim, Y., Seo, M.-G., Lee, J., 2016. Study on added resistance of a tanker in head waves at different drafts. Ocean Engineering, 111, 569-581. https://doi.org/10.1016/j.oceaneng.2015.11.026

[13] Kim, Y.C., Kim, K.S., Kim, J., Kim Y., Park, I.R., Jang, Y.H., 2017. Analysis of added resistance and seakeeping responses in head sea conditions for low-speed full ships using URANS approach. International Journal of Naval Architecture and Ocean Engineering, 9, 641-654. https://doi.org/10.1016/j.ijnaoe.2017.03.001

[14] Lee, Y.G., Kim, C., Park, J.H., Kim, H., Lee, I., Jin, B., 2019. Numerical simulations of added resistance in regular head waves on a container ship. Brodogradnja, 70(2), 61-86. https://doi.org/10.21278/brod70204

[15] Hamid S.H., Wu, P.C., Carrica, P.M., Kim, H., Toda, Y., Stern, F., 2013. CFD verification and validation of added resistance and motions of KVLCC2 with fixed and free surge in short and long head waves. Ocean Engineering, 59, 240-273. https://doi.org/10.1016/j.oceaneng.2012.12.016

[16] Arribas, F.P., 2007. Some methods to obtain the added resistance of a ship advancing in waves. Ocean Engineering, 34, 946-955. https://doi.org/10.1016/j.oceaneng.2006.06.002

[17] Moor, D.I., Murdey, D.C., 1970. Motions and propulsion of single screw models in head seas. Part II. RINA Q. Transactions, 112(2), 121-127.

[18] Ueno, M., Tsukada, Y., Tanizawa, K., 2013. Estimation and prediction of effective inflow velocity to propeller in waves. Journal of Marine Science and Technology, 18, 339-348. https://doi.org/10.1007/s00773-013-0211-8

[19] Seo, J.K., Lee, C.M., Yu, J.W., Choi, J. E., Lee, I., 2020. Power increase and propulsive characteristics in regular head waves of KVLCC2 using model tests. Ocean Engineering, 216, 108058. https://doi.org/10.1016/j.oceaneng.2020.108058

[20] Saettone, S., Taskar, B., Steen, S., Andersen, P., 2021. Experimental measurements of propulsive factors in following and head waves. Applied Ocean Research, 111, 102639. https://doi.org/10.1016/j.apor.2021.102639.

[21] Sigmund, S., Moctar, O., 2017. Numerical and experimental investigation of propulsion in waves. Ocean Engineering, 144, 35-49. https://doi.org/10.1016/j.oceaneng.2017.08.016.

[22] Lee, C.M., Seo, J.H., Yu, J.Y., Choi, J.E., Lee, I., 2019. Comparative study of prediction methods of power increase and propulsive performances in regular head short waves of KVLCC2 using CFD. International Journal of Naval Architecture and Ocean Engineering, 11, 883-898. https://doi.org/10.1016/j.ijnaoe.2019.02.001

[23] Polyzos, S.; Tzabiras, G., 2020. On the Calculation of Propulsive Characteristics of a Bulk-Carrier Moving in Head Seas. Journal of Marine Science and Engineering, 8, 786. https://doi.org/10.3390/jmse8100786

[24] ITTC, 2014. Practical Guidelines for ship Self-Propulsion CFD. Recommended Procedures and Guidelines, No. 7.5-03-03-01. https://ittc.info/media/4200/75-03-03-01.pdf , accessed on $8^{\text {th }}$ February 2022.

[25] Fenton, J.D., 1985. A fifth-order Stokes theory for steady waves. Journal of Waterway, Port, Coastal and Ocean Engineering, 111, 216-234.

[26] ITTC, 2014. Practical Guidelines for Ship CFD Applications. Recommended Procedures and Guidelines, 2014, No. 7.5-03-02-03. https://ittc.info/media/4196/75-03-02-03.pdf , accessed on 8 ${ }^{\text {th }}$ February 2022.

[27] Stern, F., Wilson, R.V., Coleman, H.W., Paterson, E.G., 2001. Comprehensive approach to verification and validation of CFD simulations-Part 1: methodology and procedures. Journal of Fluids Engineering, 123, 793-802. https://doi.org/10.1115/1.1412235

[28] Wilson, R.V., Shao, J., Stern, F., 2004. Discussion: criticisms of the "correction factor" verification method [1]. Journal of Fluids Engineering, 126, 704-706. https://doi.org/10.1115/1.1780171 
[29] SIMMAN 2014. Workshop on Verification and Validation of Ship Manoeuvring Simulation Methods, Copenhagen. https://simman2014.dk/ship-data/moeri-kvlcc2-tanker/geometry-and-conditions-moerikvlcc2-tanker/, accessed on $8^{\text {th }}$ February 2022.

[30] Larsson, L., Stern, F., Visonneau, M., 2014. Numerical Ship Hydrodynamics- An assessment of the Gothenburg 2010 Workshop, 1st ed.; Springer, Dordrecht, Netherlands. https://doi.org/10.1007/978-94007-7189-5

[31] Kim, W.J., Van, D.H., Kim, D.H., 2001. Measurement of flows around modern commercial ship models. Experiments in Fluids, 31, 567-578. https://doi.org/10.1007/s003480100332

[32] ITTC, 2011. 1978 ITTC Performance Prediction Method. Recommended Procedures and Guidelines,

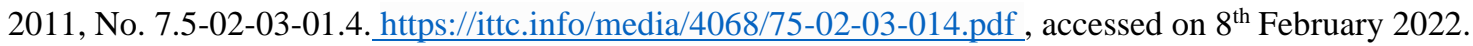

[33] Lee, S.H., Paik K.J., Hwang, H.S., Eom, M.J., Kim, S.H., 2021. A study on ship performance in waves using a RANS solver, part 1: Comparison of power prediction methods in regular waves. Ocean Engineering, 227, 108900. https://doi.org/10.1016/j.oceaneng.2021.108900

[34] Bhattacharyya, A., Steen, S., 2014. Propulsive factors in waves: A comparative experimental study for an open and a ducted propeller. Ocean Engineering, 91, 263-272. https://doi.org/10.1016/j.oceaneng.2014.09.020

Submitted: $\quad$ 09.11.2021. Kun Dai, dkhue@126.com

College of Shipbuilding Engineering, Harbin Engineering University, Harbin Accepted: $\quad$ 04.02.2022. 150001, China

Yunbo Li* (the corresponding author), multihull@163.com

College of Ocean Science and Engineering, Shanghai Maritime University, Shanghai 201306, China

Jiaye Gong, gongjiaye@ shmtu.edu.cn

College of Ocean Science and Engineering, Shanghai Maritime University, Shanghai 201306, China

Zheng Fu, fuzheng19910915@163.com

College of Shipbuilding Engineering, Harbin Engineering University, Harbin 150001, China

Ang Li, liang0301@hrbeu.edu.cn

Marine Design and Research Institute of China, Shanghai 200011, China

Dapeng Zhang, zhangdapenglsh@163.com

College of Shipbuilding Engineering, Harbin Engineering University, Harbin 150001, China 